\title{
Effect of Juglansregia and Nasturtum officinalis on biochemical parameters following toxicity of kidney by CCl4 in Wistar rats
}

\author{
Seyed Abdolazim Hosseini ${ }^{1}, 2$ Jamshid Mohammadi ${ }^{3}$, Hamdollah Delaviz $^{4}$, Mehrdad Shariati $^{5}$
}

\begin{abstract}
Background: Juglans regia contain compounds such as phenolic acids and flavonoids. Experimental studies demonstrated the Juglans regia were used in traditional medicine and has many beneficial effects. Use of Nasturtum officinalis has been reported to prevent cellular damage and elevate the level of antioxidant in the body. Nasturtum officinalis extract had Strong antioxidant properties and beneficial effects on reducing blood lipids. The purpose of this research is to determine the effect of Juglans regia and Nasturtum officinalis on biochemical parameters following toxicity of kidney by $\mathrm{CCl} 4$ in Wistar rats.

Materials and Methods: Sixty four Wistar rats were used and divided into 8 groups of eight animals each. Wistar rats were received intraperitoneally $50 \%$ CCl4 in olive oil. Juglans regia leaves and Nasturtum officinalis were orally administered before or after $\mathrm{CCl} 4$ in treatment groups twice a week for 31 days. After twenty one day, the blood samples were collected of all rats and serum levels of biochemical parameters were measured.

Results: In treatment groups, serum BUN, Bun, Alb, creatinine, Blood Urea, Uric acid levels were significantly decreased in comparison to their positive group. Also at the end of experiment, serum ALP, AST and ALT activity decreased significantly in treatment groups when compared with Positive group. Conclusion: This study suggests that $\mathrm{CCl} 4$ induced liver and kidney damage in rats can be ameliorated by administration of extract of J. regia and $\mathrm{N}$. officinalis.
\end{abstract}

Keywords: liver toxicity, kidney toxicity, Biochemical parameters, Juglans regia, Nasturtum officinalis

\section{INTRODUCTION}

The increase production of Reactive Oxygen Species (ROS) is cause by non-enzymatic reaction in the body and leads to various diseases (1). Different ROS such as hydrogen peroxide, singlet oxygen are unpaired electron and they are extremely reactive molecules (2). They could damage to the biological molecules including DNA, lipids and proteins (1). Furthermore, structural change of proteins leading to the loss of enzyme activity and they have not appropriate function against the free radicals (3). Oxidative stress created when the capacity of the enzymatic system is insufficient to neutralize the free radicals (4). With normal aging the oxidative damage increase to the cell membrane and cause degenerative disease such as cancer, heart and autoimmune disease (3). Recent studies have demonstrated it has been documented the ROS is implicated in many diseases from connective tissue to carcinogenesis (4). It has been shown that carbon tetrachloride $(\mathrm{CCl} 4)$ cause triglyceride accumulation in the liver and could create the liver steatosis (5). $\mathrm{CCl} 4 \mathrm{can}$ disrupted the lipid metabolism and lead the increase the fat droplets in the liver cells (5). Further, it has been documented that $\mathrm{CCl} 4$ leads to production of free radicals that cause different pathological changes in the renal parenchyma such as cell membrane damage, nephrotoxicity and enhance lipid peroxidation (6). Antioxidant has enormous potentials to

\footnotetext{
Department of Biology, College of sciences, Fars Science and Research Branch, Islamic Azad University, Fras, Iran

2 Department of Biology, College of sciences, Shiraz Branch. Islamic Azad university, Shiraz, Iran

3 Department of physiology, Medicinal Plants Research Center, Yasuj University of Medical Sciences, Yasuj, Iran

4 Department of Anatomy, Medicinal Plants Research Center, School of Medicine, Yasuj University of Medical Sciences, Yasuj, Iran

5 Department of Biology, Islamic Azad University, Kazerun Branch, Kazerun, Iran
}

\section{Correspondence: Jamshid Mohammadi}

Department of physiology, Medicinal Plants Research Center, Yasuj University of Medical Sciences, Yasuj, Iran

Received: 9 Jan 2018, Accepted: 11 Feb 2018

(C) 2018 by the authors; licensee Modestum Ltd., UK. This article is an open access article distributed under the terms and conditions of the Creative Commons Attribution License (http://creativecommons.org/licenses/by/4.0/). 
support the different cells from functional damage of toxic radical reaction, drug and oxidative stress (7). They have a key role in prevention of some disease such as cancer, aging, neurological disorder and cataracts (8). Recently, there has been increasing interest in the use of medicinal plants (9). Some medical plants used in many researches to protect the tissue against the oxidative stress and degenerative disease (10).

Traditionally, Juglans regia (J. regia) was used to treat diabetes, fever, skin diseases and rheumatic pains (11). J. regia leaves contained compounds such as phenolic acids and flavonoids, and the most important flavonoids present in the glands of the galactoside and quercetin pentoside derivatives, quercetin arabinoside, quercetin xyloside and quercetin umramnoside (11). N. officinalis is full of several protecting vitamins and can be used in the treatment of metabolic and chronic diseases (12). It also prevented cellular damage and increased the level of antioxidants (13). Further, N. officinalis is favorable for the evaluation of possible anti-inflammatory effects, antioxidant and antinociceptive properties (13). Since the combination of these two plants has been less studied in blood parameters this study conducted to determine the effects of Juglans regia and Nasturtum officinalis hydroalcoholic extract on blood parameters following toxicity of liver and kidney by $\mathrm{CCl} 4$ in Wistar rats.

\section{MATERIAL AND METHODS}

\section{Sample Preparation and Extraction Procedure}

The J. regia leaves and aerial parts of N. officinalis were obtained during June 2016 from Yasuj region, Yasuj, Iran. The authentication of the J. regia and N. officinalis plants were confirmed by a taxonomist in the Botany Department of Yasuj University and voucher specimens were 2-12 and 2-13 HMRC respectively. The plants washed thoroughly under running tap water, dried outside in the shade for 5 days and then ground into the fine powder using an electric mixer. The powdered of each plants material $(500 \mathrm{~g})$ was soaked in $70 \%$ ethanol at room temperature for 24 hours, a procedure repeated twice separately. The mixture was filtered using Whatman No. 1 filter paper. The solvents was removed in a rotary evaporator in vacuum at $57^{\circ} \mathrm{C}$ and dried for subsequent use. The gained extracts were kept at $-20^{\circ} \mathrm{C}$ in freezer till the time of the experiment.

\section{Animals}

Sixty four Wistar rats (6 weeks age, 200-250 g) were procured from the animal house of the Yasuj University of Medical Sciences (YUMS). All experiments were performed according to the local ethical committee in YUMS, for use and care of animals. The animals were maintained under the standard conditions based on ad libitum at room temperature $20 \pm 5^{\circ} \mathrm{C}$ with a regular 12: $12 \mathrm{~h}$ light/darkcycle. The animals were divided randomly into eight groups of eight animals. Rats in Group I (negative control) received $0.5 \mathrm{ml} / \mathrm{kg}$ body weight of distilled water orally daily and $0.5 \mathrm{ml} / \mathrm{kg}$ olive oil by intraperitoneal injection twice a week. Animals in groups 2, 3, 4, 5, 6, 7 and 8 received $1 \mathrm{ml} / \mathrm{kg}$ body weight of olive oil and $\mathrm{CCl} 4$ solution twice a week and ratio 1: 1, by intraperitoneal injection. Group 2 (positive control) received $1 \mathrm{ml} / \mathrm{kg}$ body weight of olive oil and CCl4 solution twice a week and ratio 1: 1 by intraperitoneal injection. Group 3 and 4 treated with hydroalcoholic extract of J. regia leaves at a dose of 200 and $400 \mathrm{mg} / \mathrm{kg}$ gavage daily respectively. Group 5 and 6 treated with hydroalcoholic extract of N. officinalis leaves at a dose of 250 and $500 \mathrm{mg} / \mathrm{kg}$ gavage daily respectively. Group 7 treated with hydroalcoholic extract of J. regia leaves and N. officinalis leaves at a dose of 200 and $250 \mathrm{mg} / \mathrm{kg}$ gavage daily respectively. Group 7 treated with $50 \mathrm{mg} / \mathrm{kg}$ body weight Silymarin standard drug dissolved in normal saline by gavage daily. All groups treated for 31 days.

\section{Serum Biochemistry}

At the end of experimental, the animals were fasted overnight and sacrificed by cervical dislocation after collection of blood samples. Samples were transferred to Hospital's Laboratory for measuring BUN, albumin, Blood Urea, total protein, bilirubin total, bilirubin direct, creatinine, Uric acid and activity levels of AST, ALT and ALP. Blood samples were separated with high speed centrifuge at $3500 \mathrm{rev/minute} \mathrm{for} 10$ minutes and serum was separated by Pasteur pipette for analysis of the biochemical assays.

\section{Statistical Analysis}

All data are expressed as mean \pm SEM, One-way ANOVA was used for data analysis, followed by the Tukey test for post hoc analysis. A P-value $<0.05$ was considered to be statistically significant. 
Table 1: Effect of J. regia leaves and $N$. officinalis on serum activities of $A L P, A L T, A S T, B U N, A l b$, creatinine, blood urea and uric acid on different groups

\begin{tabular}{|c|c|c|c|c|c|c|c|c|}
\hline Groups & Al & AST & L) & IN & J & $\begin{array}{c}\text { Creatinine } \\
(\mathrm{mg} / \mathrm{dl})\end{array}$ & $\begin{array}{c}\text { Blood Urea } \\
(\mathrm{mg} / \mathrm{dl})\end{array}$ & $\begin{array}{l}\text { Uric acid } \\
(\mathrm{mg} / \mathrm{dL})\end{array}$ \\
\hline Negative Control & $109.50 \pm 7.2^{\mathrm{a}}$ & $2.66 \pm$ & $6.00 \pm 17.28^{a}$ & 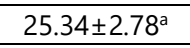 & ( & $0.63 \pm 0.13^{\mathrm{a}}$ & $24.61 \pm 1.95^{\mathrm{a}}$ & \\
\hline Positive Control & $5.75^{b}$ & & & & & & & \\
\hline Treatment 1 & & & & & & & & \\
\hline Treatment 2 & & & & & & & & \\
\hline Treatment 3 & $1^{\mathrm{b}}$ & $350.16 \pm$ & $8^{\mathrm{a}}$ & $1^{\mathrm{b}}$ & $9^{a}$ & $13^{b}$ & $1^{\mathrm{b}}$ & $55^{b}$ \\
\hline Treatment 4 & $0.73 \pm 12.05^{\mathrm{a}}$ & & $674.66 \pm 12.44^{\mathrm{a}}$ & & & & 27.68 & $0.79^{a}$ \\
\hline Treatment 5 & & & & & & & $25.70 \pm 1.90^{\mathrm{a}}$ & \\
\hline Treatment 6 & $118.33 \pm 12.63^{a}$ & $288.50 \pm 8.06^{\mathrm{a}}$ & $727.33 \pm 10.67^{\mathrm{a}}$ & $21.00 \pm 1.77^{\mathrm{a}}$ & $3.46 \pm 1.31^{\mathrm{a}}$ & $0.73 \pm 0.11^{\mathrm{a}}$ & $26.05 \pm 2.31^{\mathrm{a}}$ & $1.39 \pm 0.68^{\mathrm{a}}$ \\
\hline
\end{tabular}

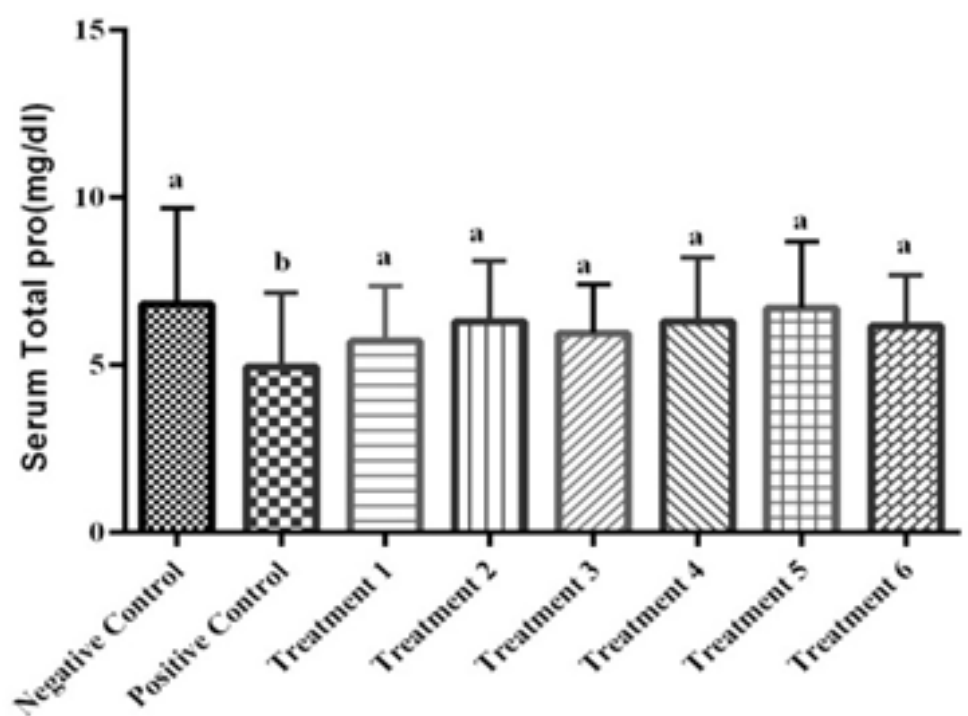

Groups

Figure 1: The effect of J. regia leaves and $N$. officinalis on total protein levels in different groups $(p<0.05)$. The vertical bars are showing mean values of bilirubin total. Lines above the bars indicate standard error (SEM). The word (b) indicates that $P<0.05$ when comparing positive control group to negative control group. The word (a) indicates that $P<0.05$ when comparing treated groups to positive control group

\section{RESULTS}

Effects of J. regia leaves and N. officinalis on serum ALT, AST, ALT, Bun, Alb, creatinine, Blood Urea, Uric acid in all groups from various treatment groups are shown in Table 1. In Positive group, serum BUN, Bun, creatinine, Blood Urea, Uric acid, ALP, AST and ALT activity were significantly increased in comparison to their Negative group. At the end of experiment, serum ALP, AST and ALT activity decreased significantly in treatment groups of 2, 3, 4 and 5 when compared with Positive group $(p<0.05)$ (Table 1).

In addition, Table 1 shows changes in blood Albumin levels after 31 days. Albumin were decreased significantly in the positive control group (Group II) and brought to the near level as the negative control group in treatment groups $(p<0.05)$. The hydroalcoholic extract of $J$. regia and $N$. officinalis had a significant effect on lowering blood Albumin $(p<0.05)$ (Table 1).

The positive control group exhibited, the total protein level showed a significant decrease as compared to the negative group $(p<0.05)$. In addition, the present findings indicate that administration of administrating 200 and 400 $\mathrm{mg} / \mathrm{kg} \mathrm{BW}$ of $J$. regia leaves and 250 and $500 \mathrm{mg} / \mathrm{kg}$ bw of $N$. officinalis and silymarin ( $50 \mathrm{mg} / \mathrm{kg} \mathrm{bw}$ ) lead to significant increase in serum total protein levels in treatment groups as compared with Positive group $(p<0.05)$ (Figure 1).

The positive control group exhibited, the bilirubin direct level showed a very highly significant increase as compared to the negative group $(p<0.05)$. The oral administration of $\mathrm{J}$. regia and $\mathrm{N}$. officinalis produced marked improvement of the bilirubin direct level of the treatment groups as compared with positive group $(p<0.05)$ (Figure 2$)$. 


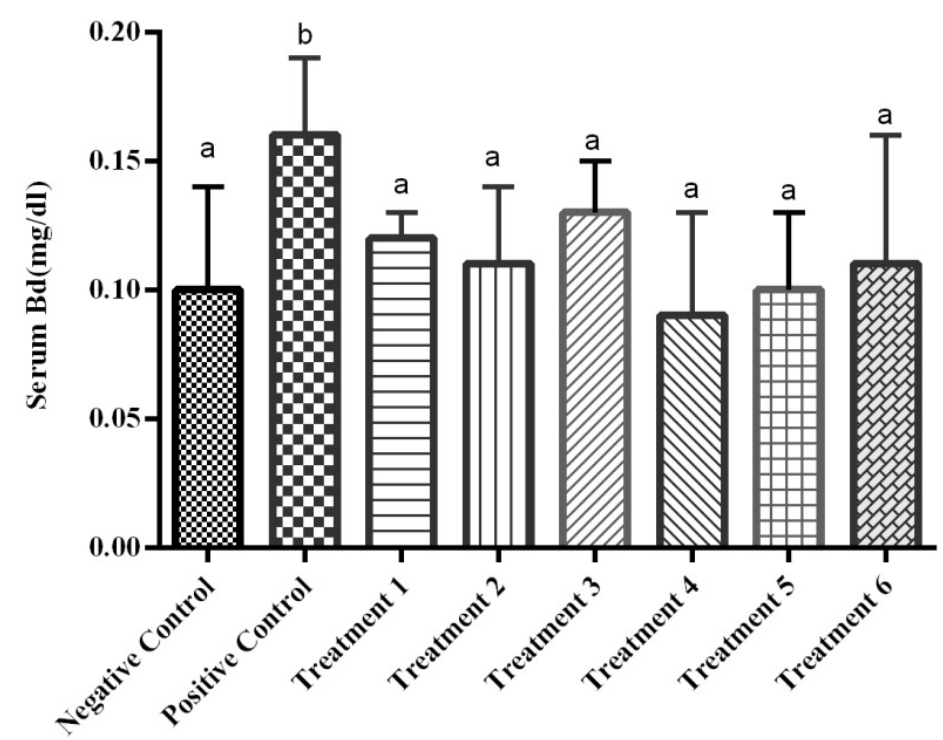

Figure 2: The effect of $J$. regia leaves and $N$. officinalis on bilirubin direct level in different groups $(p<0.05)$. The vertical bars are showing mean values of bilirubin total. Lines above the bars indicate standard error (SEM). The word (b) indicates that $P<0.05$ when comparing positive control group to negative control group. The word (a) indicates that $P<0.05$ when comparing treated groups to positive control group

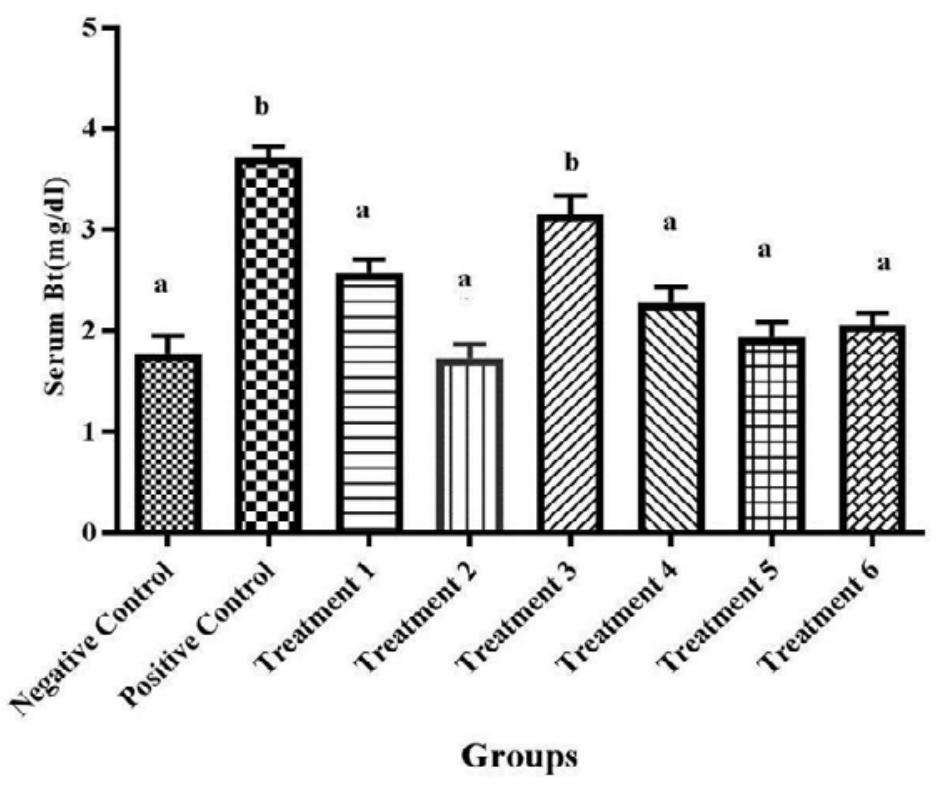

Figure 3: The effect of J. regia leaves and N. officinalis on bilirubin total levelsin different groups $(p<0.05)$. The vertical bars are showingmean values of bilirubin total. Lines above thebars indicate standard error (SEM). The word (b) indicates that $P<0.05$ when comparing positive control group to negative control group. The word (a) indicates that $P<0.05$ when comparing treatment groups 1, 2, 4, 5, 6 and 7 to positive control group

Also the positive control group exhibited, the bilirubin total level showed a very highly significant increase as compared to the negative group $(p<0.05)$. The oral administration of J. regia and $\mathrm{N}$. officinalis produced marked improvement of the bilirubin total level of the treatment groups as compared with positive group $(p<0.05)$ (Figure 3 ).

\section{DISCUSSION}

In the present study the $\mathrm{CCl} 4$ treatment caused severe acute liver damage in rats, as evidenced by increased serum AST, ALT, BUN, Bun, Creatinine, Blood Urea, Uric acid and a decreased serum Alb level. Measurement of the activities of 
serum marker enzymes, like AST, ALT and ALP, can make assessment of liver function (14). In this study, ALP, AST and ALT activities increased in the Positive group that was treated with $\mathrm{CCl} 4$ alone, indicating damage to the liver tissue by $\mathrm{CCl} 4$ induced hepatotoxicity $(\mathrm{p}<0.05)$.

It has been shown that among the different species, the highest activity of catalase and Peroxidase activity was observed in $N$. officinalis (15). The antioxidant potential of plant extracts is related with their phenolic content. Phenolic and flavonoid compounds in plants, have potent antioxidant activity, due to they have a functional group with antioxidant and scavenging activities (16). The hepatotoxic effects of $\mathrm{CCl}_{4}$ are mostly caused by peroxidation of lipids and the presence of the free radicals (17). In the recent work, the hepatotoxicity was demonstrated by significant increases in the activity of AST, ALT and ALP enzyme markers in $\mathrm{CCl}_{4}$ treated animals compared to normal group. Determination of ALP activity in plasma is a sign of hepatocyte function (18). In toxic group that treated with CCL4, the ALP was significantly increased due to damage to liver tissue. However, AST, ALP and ALT activities in the treated with J. regia leaves and $N$. officinalis groups were lower than that of the Positive group. This finding suggests that $J$. regia leaves and $N$. officinalis work to protect and repair liver tissue from injury. These results confirm those of previous reports (19, 20). Moreover, our findings suggest that dosages may be an important factor for curative effects of J. regia leaves and $\mathrm{N}$. officinalis. In another study, oral administration of the hydroalcoholic extract of the $\mathrm{N}$. officinalis leaf reduced the serum ALT and AST levels compared with high fat diet groups (20).

An obvious sign of hepatic injury is leakage of cellular enzyme into plasma (21). When the liver cell plasma membrane is damaged, a variety of enzymes normally located in the cytosol are released into blood stream. Their estimation in the serum is a useful quantitative marker for the extent and type of hepatocellular damage (22).

Decrease in serum bilirubin after treatment with the extract in liver damage indicated the effectiveness of the extracts in normal functional status of the liver. This is in agreement with the report by Ahmed et al. (23). Hypoalbuminemia and decline in total protein content can be deemed as a useful index of severity of hepatocellular damage. The lowered levels of Albumin and total protein recorded in the serum as well as in the liver of CCl4-treated rats reveal the severity of hepatopathy (24). From the result of this study, and other findings about antioxidant properties of silymarin, it can be firmly claimed that the antioxidant activity of silymarin leads to improve the change observed in sham rats (25).

Administration of hydroalcoholic extract of J. regia leaves increases the HDL and insulin and decreases cholesterol, triglycerides and LDL (16). The J. regia extract reduces systolic and diastolic blood pressure. It also increased plasma renin levels and significantly reduced the ratio of aldosterone to rennin (17). In another study, the effect of hydroalcoholic extract of $\mathrm{N}$. officinalis leaves on the lipid profile in rats in diabetic rats has been investigated. The results showed that oral administration of hydroalcoholic extract of N. officinalis leaves $(500 \mathrm{mg} / \mathrm{kg})$ for 10 days reduced serum TC, TG and LDL-C levels respectively, the serum C-HDL level increased (20). Oral administration of the hydroalcoholic extract of the $\mathrm{N}$. officinalis leaf reduced the serum ALT and AST levels compared with high fat diet groups. Based on these findings, the $\mathrm{N}$. officinalis has a potential for cardiovascular protection and can be used to treat it (18-20).

\section{CONCLUSION}

According to the results suggest that the $\mathrm{CCl} 4$ induced liver damage in rats can be ameliorated by administration of hydroalcoholicextract of $\mathrm{J}$. regialeaves and $\mathrm{N}$. officinalisand improve biochemical factors near to normal.

\section{CONFLICT OF INTEREST}

The authors declare no conflict of interests.

\section{REFERENCES}

1. Vahidirad M, Arab-Nozari M, Mohammadi H, Zamani E, Shaki F. Protective effect of captopril against diazinon induced nephrotoxicity and neurotoxicity via inhibition of ROS-NO pathway. Drug ChemToxicol 2017;8:1-7. https://doi.org/10.1080/01480545.2017.1391830

2. Nazari M, Zarinkamar F, Shafaghat Z. Manganese modulates the physiological and biochemical responses of Mentha aquatica L. to ultraviolet radiation. J Trace Elem Med Biol. 2018;45:1-10. https://doi.org/10.1016/j.jtemb.2017.08.015 PMid:29173464

3. Baeeri M, Mohammadi-Nejad S, Rahimifard M, Navaei-Nigjeh M, Moeini-Nodeh S, Khorasani R, et al. Molecular and biochemical evidence on the protective role of ellagic acid and silybin against oxidative stress-induced cellular aging. Mol Cell Biochem 2017;433:1-13. https://doi.org/10.1007/s11010-017-3172-0 
4. Okada F. Beyond foreign-body-induced carcinogenesis: impact of reactive oxygen species derived from inflammatory cells in tumorigenic conversion and tumor progression. Int J Cancer 2007;121:2364-72. https://doi.org/10.1002/ijc.23125 PMid:17893867

5. Kato $\mathrm{H}$, Nakazawa Y. Carbon tetrachloride and trichloroethylene toxicities to rat hepatocytes in primary monolayer culture: its relationship to the level of cytochrome P-450. Toxicol Lett. 1986;34:55-66. https://doi.org/10.1016/0378-4274(86)90145-1

6. Borges Sda S, Korn M, Lima JL. Chromium (III) determination with 1, 5-diphenylcarbazide based on the oxidative effect of chlorine radicals generated from CCl4 sonolysis in aqueous solution. Anal Sci. 2002;18:1361-6. https://doi.org/10.2116/analsci.18.1361 PMid:12502090

7. Pawar R, Mohandass C, Sivaperumal E, Sabu E, Rajasabapathy R, Jagtap T. Epiphytic marine pigmented bacteria: A prospective source of natural antioxidants. Braz J Microbiol. 2015;46:29-39. https://doi.org/10.1590/S1517838246120130353 PMid:26221086 PMCid:PMC4512047

8. Mukherjee S, Thakur G, Kumar BD, Mitra A, Chakraborty C. Long-term effects of a carbohydrate-rich diet on fasting blood sugar, lipid profile, and serum insulin values in rural Bengalis. J Diabetes 2009;1:288-95. https://doi.org/10.1111/j.1753-0407.2009.00050.x PMid:20923529

9. Mohammadi J, Naik PR. Antidiabetic effects of Morus alba in experimentally induced diabetes in Wistar rat. Biomedicine 2008;28:112-116.

10. Yuan LP, Chen FH, Ling L, Bo H, Chen ZW, Li F, et al. Protective effects of total flavonoids of Bidensbipinnata L. against carbon tetrachloride-induced liver fibrosis in rats. J Pharm Pharmacol 2008;60:1393-402. https://doi.org/10.1211/jpp.60.10.0016 https://doi.org/10.1211/jpp/60.10.0016 PMid:18812033

11. Delaviz H, Mohammadi J, Ghalamfarsa Gh, Mohammadi B, Farhadi N. A review study on Phytochemistry and pharmacology applications of Juglans regia plant. Pharmacognosy Reviews 2017;11:57-64.

12. Mohammadi J, Taheri Motlagh F, Mohammadi N. The effect of hydroalcoholic extract of watercress on parameters of reproductive and sex hormones on the diabetic rats. J Pharm Sci Res. 2017;9:1334-38.

13. Shahani S, Behzadfar F, Jahani D, Ghasemi M, Shaki F. Antioxidant and anti-inflammatory effects of Nasturtium officinale involved in attenuation of gentamicin-induced nephrotoxicity. Toxicol. Mech. Methods. 2017;27:107114. https://doi.org/10.1080/15376516.2016.1258748 PMid:27825290

14. Porchezhian E, Ansari SH. Hepatoprotective effect of Abutilon indicumon experimental liver damage in rats. Phytomed 2005;12:62-64. https://doi.org/10.1016/j.phymed.2003.09.009 PMid:15693709

15. Keser G, Saygideger S. Effects of lead on the activities of antioxidant enzymes in watercress, Nasturtium officinale R. Br. Biol Trace Elem Res. 2010;137:235-43. https://doi.org/10.1007/s12011-009-8573-9 PMid:19967468

16. Mohammadi J, Chatrroz B, Delaviz H. The effect of hydroalcoholic extract of capparis spinosa on quality of sperm and rate of testosterone following induction of diabetes in rats. Journal of Isfahan Medical School 2014;31:1-11.

17. Banothu V, Neelagiri C, Adepally U, Lingam J, Bommareddy K. Phytochemical screening and evaluation of in vitro antioxidant and antimicrobial activities of the indigenous medicinal plant Albizia odoratissima. Pharm Biol. 2017;55:1155-1161. https://doi.org/10.1080/13880209.2017.1291694 PMid:28219296

18. Johnston $D E$, Kroening $C$. Mechanism of early carbon tetrachloride toxicity in cultured rat hepatocytes. Pharmacol Toxicol. 1998;83:231-9. https://doi.org/10.1111/j.1600-0773.1998.tb01475.x

19. El-Hadary AE, Ramadan Hassanien MF. Hepatoprotective effect of cold-pressed Syzygium aromaticum oil against carbon tetrachloride (CCl4)-induced hepatotoxicity in rats. Pharm Biol. 2016;54:1364-72. https://doi.org/10.3109/13880209.2015.1078381 PMid:26440388

20. Lee HS, Li L, Kim HK, Bilehal D, Li W, Lee DS, et al. The protective effects of curcuma longa linn. extract on carbon tetrachloride-induced hepatotoxicity in rats via up regulation of Nrf2. J Microbiol Biotechnol. 2010;20:1331-38. https://doi.org/10.4014/jmb.1002.03010

21. Shahrokhi N, Hadad M, Shabani M. Effects of aqueous extract of water cress on glucose and lipis plasma in streptozotocin induced diabetic rats. Pakistan Journal of Physiology 2009;5:6-10.

22. Schmidt E, Schmidt FW, Mohr J, Otto P, Vido I, Wrogeman, K, et al. Liver morphology and enzyme release. Further studies in the isolated perfused rat liver. In: Keppler (Ed.) Pathogenesis and Mechanism of Liver Cell Necrosis. Medical and Technical Publishing Co. Ltd., Lancaster 1975;147.

23. Ansari RA, Tripathi SC, Patnaik GK and Dhawan BN. Antihepatotoxic properties of picroliv, an active fraction from rhizomes of Picrorhiza kurroa. J Ethnopharmacol. 1991;34:61-68. https://doi.org/10.1016/0378-8741(91)90189$\mathrm{K}$ 
24. Ahmed MB, Hasona NAS, Selemain HAH. Protective effects of extract from dates (Phoenix dactyliferal.) and ascorbic acid on thioacetamide-induced hepatotoxicity in rats. Iranian Journal of Pharmaceutical Research 2008;7:193-201.

25. Aniya $Y$, Koyama $T$, Miyagi $C$, Miyahira M, Inomata $C$, Kinoshita $S$, Ichiba T. Free radical scavenging and hepatoprotective actions of the medicinal herb, Crassocephalum crepidioides from the Okinawa Islands. Biol Pharm Bull 2005;28:19-23. https://doi.org/10.1248/bpb.28.19 PMid:15635156

26. Pradeep K, Mohan CVR, Gobianand K, Karthikeyan S. Silymarin modulates the oxidant-antioxidant imbalance during diethylnitrosamine induced oxidative stress in rats. Eur J Pharmacol. 2007;560:110-116. https://doi.org/10.1016/j.ejphar.2006.12.023 PMid:17300777

$\diamond \diamond \diamond \diamond \diamond \diamond \diamond$

http://www.ejgm.co.uk 